\title{
Aesthetic Experience Anchors Ego Identity Formation
}

\author{
Chi-Ying Yu ${ }^{1}$ and Po-Ching Wang ${ }^{2, *}$ \\ 1 Department of Arts and Design, National Tsing Hua University, 521 Nan-Da Road, Hsinchu 30014, Taiwan; \\ chiying.yu@mx.nthu.edu.tw \\ 2 Department of Landscape Architecture, National Chiayi University, 300 Syue-Fu Road, Chiayi 60004, Taiwan \\ * Correspondence: gaiascape@hotmail.com or pcwang@mail.ncyu.edu.tw; Tel.: +886-920-037-606
}

Received: 7 April 2018; Accepted: 6 July 2018; Published: 24 July 2018

check for

Abstract: The development of a coherent identity status, also referred to as ego identity, is critical during adolescence and early-adulthood. In the long run, an individual's ego identity status may influence the sustainability of his or her well-being. Researchers have attempted to discover the predictors or factors correlated with one's identity status. In that search, aesthetic experience, as a unique means of knowing oneself and the world, seemed to be overlooked. Philosophical and psychological discourses have asserted that aesthetic experience stimulated identity discovery and formation; this hypothesis, however, is not supported by strong quantitative evidence. Thus, an empirical study with a quantitative approach was conducted to examine whether those who have frequent aesthetic experiences are more likely to possess a mature ego identity. A sample of 758 valid questionnaires was collected. The results supported the argument that aesthetic experience favors the development of ego identity. In addition, this study revealed that sociodemographic backgrounds such as women, fine arts and design majors, and religious individuals were more likely to have a rich aesthetic life. The results imply that aesthetic experience serves as a crucial aspect that contributes to the wellness of personality development and promotes a healthy and sustainable quality of life.

Keywords: aesthetic sensitivity; ego identity; individual sustainability; emerging adult

\section{Introduction}

The psychology of sustainability and sustainable development extends its focus from sustainability of environmental and economic dimensions to the personal and collective quality of life [1,2]. Its concern is not only with ways to avoid resource depletion but also with how to create potentially rich and diverse development [1]. In its micro-dimension, the vertical axis, the sustainability of an individual's development relies on a capacity for reflection, and an awareness of one's past, present, and future. A sustainable state of positive living and psychological well-being is the primary focus of this emerging area [1]. Similarly, ego identity describes an individual's capacity for self-verification and its continuity [3,4]. Regarding ego as an intrinsic power that plays a constructive role of the self, Erikson refers ego identity to an increasingly coherent self-cognition under subtle psychodynamics and the joint influences of personal life history, self-belief, perceptions of others, and social values [4].

Marcia [5] adapted Erikson's model to investigate and define adolescents' experiences in terms of aspects such as occupation, religion, and politics. In subsequent studies, the model was gradually extended to other aspects such as sexual behavior, friendship, dating, and sexual roles [6-8]. In Marcia's model, a matrix consisting of two dimensions (exploration and commitment) forms four quadrants to differentiate the development of individuals' ego identity as follows: identity achievement (high exploration and high commitment), identity moratorium (high exploration and low commitment), 
identity foreclosure (low exploration and high commitment), and identity diffusion (low exploration and low commitment) [5,9]. These four quadrants have long been used in academic communities as key indicators of personality development among adolescents and emerging adults [10].

The formation of a coherent ego identity is especially crucial during adolescence [3,4]. In the long run, an individual's ego identity may influence the sustainability of his or her well-being. Research has shown that from adolescence to adulthood, individuals who have developed an integrated self-identity and have a clear view about the future tend to be more capable of facing challenges [11,12]. They often have higher psychological well-being $[13,14]$. Those who achieve a coherent sense of identity also perform better in most positive psychology indicators, such as eudaimonic well-being, the presence of meaning in life, and self-esteem [14].

Since the maturation of the ego identity is crucial, researchers have attempted to discover the predictors or the factors correlated to one's identity status. For example, females are found in higher identity statuses than males for biological [15] and social reasons [16]. Some studies have explored the influence of cognition styles on a person's identity status [17,18]. While forms of cognition vary, aesthetic experience, as a unique means of knowing oneself and the world, seems to be overlooked. When the discipline of aesthetics was born in the 18th century, Alexander Baumgarten regarded aesthetics as the "science of sensual cognition" [19]. Based upon this definition, aesthetic experience is a process involving both perception and cognition. In a recent neuro-aesthetic study, aesthetic appreciation was regarded as the interactive response between the cognitive and the emotional [20].

In fact, countless philosophers, psychologists, and artists have stated that the aesthetic experience echoes the sense of existence, self-consciousness, and the innate needs of an individual [21]. For example, Dewey [22] argued that individuals can gain a sense of complete and integrated pleasure through aesthetic experience. Maslow's hierarchy of needs asserts that aesthetic needs are antecedent to self-actualization and self-transcendence [23-27]. The abstract expressionist painter Jackson Pollock argued that "Painting is a state of being ... Painting is self-discovery. Every good painter paints what he is" [28]. Such discourse implies that the aesthetic experience triggers or inspires people's egos to a certain extent.

Even though the relationship between aesthetic experiences and the self is widely recognized [21], there are very few empirical studies that confirm this relationship. Moreover, specific discussions of how aesthetic experiences affect ego identity are rare. A small amount of qualitative data accrued from interviews and recorded personal experiences have confirmed that an individual's self-identity can be reflected through a powerful aesthetic experience [29-31]. Such intense encounters with aesthetic expression may even lead to a state of non-self [31-33]. Few quantitative empirical researches have implied a possible correlation between aesthetic sensitivity and personality traits, such as open-mindedness [34,35], "tolerance of complexity", "independent judgment", and "regression in the service of the ego" [34]. Waterman and Goldman's study [35] is a rare case that indicates a direct association between aesthetic literacy and the development of ego identity. It has been observed that culturally sophisticated college students, and those interested in various literary and art forms had a higher probability for achieving coherent identity in the future. However, these researches focused primarily on art-oriented aesthetic activity and were more concerned with the cognitive dimension of aesthetic encounters, rather than their experiential quality.

To bridge these research gaps, the core objective of this study is to clarify whether individuals who frequently have aesthetic experiences exhibit more consistent ego stability and self-identity. Should the aforementioned relationship be confirmed, it would be important to further explore the sociodemographic background that may create conditions favorable to the sensing of aesthetic experiences. To this end, quantitative approaches are conducted among a population of Taiwanese college students. A questionnaire is developed to find out and correlate the respondents' frequency of aesthetic experiences, ego-identity status, and their sociocultural attributions.

The rest of the paper is structured as follows: Section 2 reviews the literature on how one's sense of self is aroused and constructed in diverse aesthetic experiences. The literature reviewed in this 
section serves as the foundation of the primary research hypothesis. To develop the secondary research hypothesis, Section 3 discusses the relationship between one's sociocultural background and aesthetic life. Section 4 describes the research design in detail, including participants, measures, procedure, and methods of data analysis. Section 5 presents the results of data analysis to confirm the validity of the research hypotheses. Section 6 synthesizes the findings of the study and the literature reviewed in previous sections. Section 7 summarizes the study, draws educational implications, and proposes possible directions for future research.

\section{Identity Discovery and Formation through Aesthetic Experience}

The appreciation and creation of artworks are closely related to an individual's ego and self-identity. Freud asserted that artworks reveal the phantasy shared between artist and audience. During the sublimation of phantasy, viewers obtain a deep level of pleasure that adjusted their ego identification [36]. Winnicott $[37,38]$ stated that the origin of artistic creation is traced back to infancy, and infants differentiate themselves from others based on the first not-me possession created when a transitional object substitutes for their mother. In addition, the moderating effect created by the transitional object subsequently expands into artistic activities among human society. Similarly, Bollas argued that the fulfilment of needs during infancy, where individuals explore their existence and self-significance, is the origin of aesthetic experience [36]. However, regarding the fine arts merely as a reflection of original experience or self-expression overlooks the aspects of initiatives and plasticity of the ego. The ego is not a static state. During the creative process, the seemingly unconscious operations are affected by self-consciousness (i.e., ego). Artistic creation is a process that involves objectifying a subject, externalizing the ideal self, and remolding the self [39].

Neurological experiments have confirmed an association between an individual's artistic tastes and their self-identity. Vessel et al. [40] have reported that according to functional magnetic resonance imaging, when preferred artwork is viewed, the default mode network of the participant, which is the neural region that deals with self-referential and self-relevant tasks and information, is activated. Therefore, the process of evaluating art is a mental activity that reaches the depths of the self and the ego.

The generation of aesthetic experience is not limited to artistic experience. Everyday life can be a source of aesthetic experience [41-44]. In ancient times, when the concept of art was absent, elements of creativity were already being incorporated into the production of ceremonial artefacts and daily essentials. It is even hypothesized that aesthetic experience stimulates the development of the conceptual self, thereby supporting a consistent self-image that satisfies the non-stop process of the pursuit of the self [45]. Therefore, aesthetic experience may promote an individual's advanced cognitive development to a certain extent.

Nature is another key field where aesthetic experience occurs. Kant [46] elaborated on the concept of sublime in aesthetics as a supreme sensual experience of nature's formlessness, brute force, and vast quantity. People perceive their limits and insignificance in relation to eternal and infinite natural phenomena, thereby subliming into a moral and emotional experience. Hepburn [47-49], who specialized in environmental aesthetics, argued that the beauty of nature unifies an individual's inner self. In contrast to the sense of distance in artwork appreciation, individuals surrounded by nature are more likely to think metaphysically about their existence and reality. Similar to the self-dialectical dynamics involved in artistic activities, individuals can clarify their situations through the contradictions and conflicts inherent in nature. The concept of tian-ren-he-yi (the union of the universe and human beings) in Chinese aesthetics vividly conveys a sense of self-integration through aesthetic experience and constitutes the optimal harmonious coexistence of humans, nature, spirits, and the universe [50]. During interviews on aesthetic experience, Ferrucci [30] found that a large proportion of respondents perceived a more concrete existence and affirmed their self-worth when immersed in natural beauty. 
Based upon the above discussion, when an individual has an aesthetic experience, the self is operating in diverse ways under various circumstances. Moreover, aesthetic experiences seem to engage, stimulate, and activate the self. In which case, could it help individuals explore and commit to different orientations of their identity? The main research hypothesis in this study is as follows:

Primary Hypothesis (H1). Individuals who have frequent aesthetic experiences are more likely to possess a mature ego identity. That is, aesthetic experience favors the development of ego identity among emerging adults.

\section{Social Contexts that Nourish Rich Aesthetic Experiences}

When we say that someone often has aesthetic experiences, it generally indicates two possibilities. First, the person is more aesthetically sensitive than others. In other words, aesthetic sensitivity is an inherent personality trait. When Smolewska et al. [51] reevaluated the Highly Sensitive Person Scale developed by Aron and Aron [52], they distinguished three components of sensory-processing sensitivity. Aesthetic sensitivity was one of them. It involves an awareness, reactivity, and responsiveness to aesthetic phenomena. They identified a moderate correlation between aesthetic sensitivity and the quality of openness to experience dimension in Costa and McCrae's "Big Five" personality traits [53]. As a personality trait, openness to experience refers to being open to new ideas, sensitive to innate feelings, and possessing a keen imagination [53].

Second, having frequent aesthetic experiences is related to extrinsic factors. That is, a certain lifestyle makes it easier for some people to access aesthetic media, and therefore enjoy aesthetic experiences often. From the sociological perspective, aesthetic experience should not be a phenomenon detached from cultural contexts. As Bourdieu [54] noted, some social conditions may constitute an advantageous resource for individuals' perceptions of aesthetic experiences. Art competence is essentially cultural capital cultivated by formal and informal education and a necessary condition to enter the realm of fine arts, propose appropriate interpretations, and display a high level of artistic taste. Studies reveal that people with a higher socioeconomic status often have better aesthetic judgment. Their judgment of artworks, at least, is close to that of an expert's [34,55].

Returning to the realm of psychology, do certain types of lifestyles provide individuals with opportunities to immerse themselves in particular psychological states and indirectly develop the aforementioned aesthetic sensitivity traits? The ultimate state of aesthetic experience may refer to the spiritual quality experienced by a focused individual during a flow experience $[21,56,57]$ or the peak experience of completeness, fulfilment, and trance caused by feelings of ecstasy and high emotional tension. In addition to aesthetic experience, religious experiences, parenting experiences, sexual experiences, etc. may all bring about a peak experience [24]. In brief, the psychological state evoked by aesthetic experiences also has many forms. Meanwhile, some other experiences share similar mental states to aesthetic experiences. Would psychological qualities similar to aesthetic experiences rehearse an individual's capacity for aesthetic experiences? For example, due to the similarity between religious experiences and aesthetic experiences, would a person who has had frequent religious experiences be more likely to be moved by aesthetic phenomena? Note that by religious experience, Maslow refers to the subjectively mystic experience that is awakened by religious belief but is not necessarily associated to organized religious groups [24].

To summarize, the frequency of aesthetic experiences depends on the individual's living conditions. Moreover, aesthetic sensitivity as a personality trait may be influenced by social factors. The secondary hypothesis of this research attempts to clarify the sociodemographic factors that correlate with the characteristics of aesthetically sensitive individuals.

Secondary Hypothesis (H2). Some sociodemographic backgrounds (e.g., gender, religious affiliation, education, and economic status) favor the frequency of a person's aesthetic experiences. That is, these contexts determine whether or not a person enjoys a rich aesthetic life. 
The research framework (Figure 1) that integrates H1 with H2 is shown as follows:

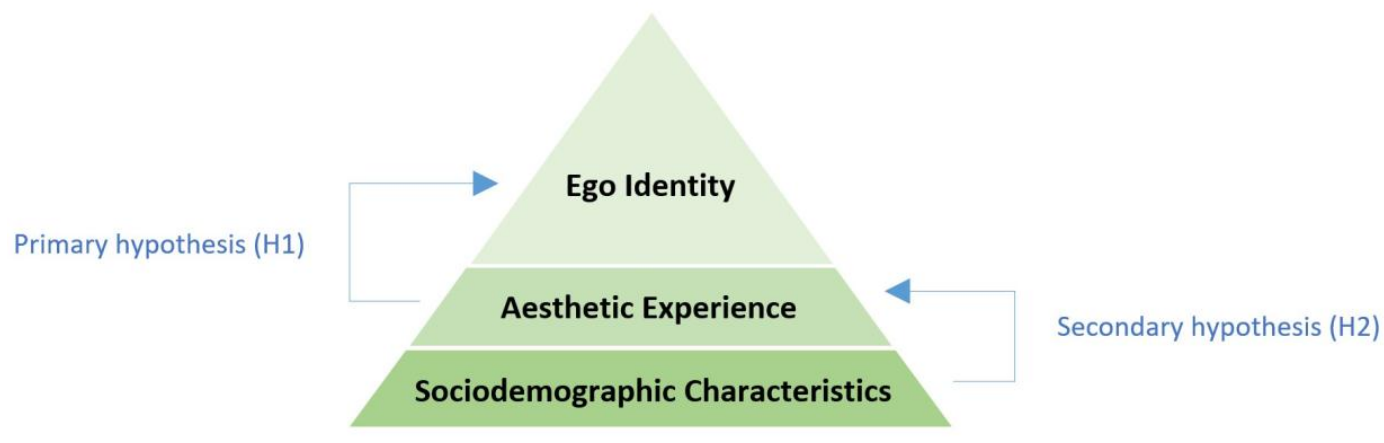

Figure 1. Research framework.

\section{Method}

\subsection{Participants}

The participants in this study were students enrolled at universities in Taiwan during the study period. The ego identity process questionnaire (EIPQ) was originally developed specifically for college students [58]. Most college students are in the transitional age phase between adolescence (a critical stage in the development of ego identity) and young adulthood [3,4]. Therefore, college students are regarded as the ideal population for verifying the development of ego identity [59-62]. In addition, most college students in Taiwan undergo a period of "extended adolescence" because of protection and restraints from parents and school [63]. Therefore, assessing Taiwanese college students' ego identity and aesthetic experience should prove a worthwhile pursuit.

\subsection{Measures}

This study investigated the relationship between aesthetic experience (IV) and individuals' ego identities (DV) through a quantitative analysis. The aesthetic experience scale (AES) developed by Stamatopoulou [64] was adapted and revised to measure the frequency of an individual's aesthetic experience. To measure the development of ego identity, this study revised the commonly used EIPQ developed by Balistreri et al. [58].

The AES uses a 5-point Likert scale ranging from 1 (never occurred) to 5 (frequently occurring). The scale consists of 28 items to measure the frequency of various artistic and non-artistic aesthetic encounters. The AES fits the research scope and focuses on both emotional and cognitive dimensions of such experience. The development of the AES summarizes the understanding and description of aesthetic experience in philosophical and psychological terms [64]. The scale comprises the following five dimensions: cognitive synergies and elaboration, emotional closeness, experiential emotional distancing, the paratelic mode, and expressive perception.

The EIPQ uses a 6-point Likert-type scale ranging from 1 (strongly disagree) to 6 (strongly agree). The scale consists of 32 items under the two dimensions of exploration and commitment and measures an individual's status in terms of the following eight categories: occupation, religion, politics, values, family, friendships, dating, and sex roles. The EIPQ is an extensively used scale that measures ego identity status in specific groups. For example, Crocetti et al. [65] employed the EIPQ to compare the ego identity among Italian adolescents from various ethnic backgrounds. The EIPQ can also be used to explore associations between ego identity and other topics such as preference in choosing spouse [66] and spirituality [67].

For consistency with logic in the Chinese language and Taiwanese cultural contexts, this study created Chinese versions of the questionnaire items through forward and backward translation, expert reviews, and several pre-tests. The finalized versions of these two scales contain not only AES and EIPQ 
items but also respondents' sociodemographic information including sex, college major, economic status, and religious affiliation. The sociodemographic information was incorporated to determine the correlation between sociodemographic background and the frequency of aesthetic experiences, thereby providing an in-depth understanding of aesthetic experience and identifying the demographic variables that favor the accumulation of personal aesthetic experience.

\subsection{Procedure}

The formal questionnaire was distributed in May and June 2016. This study selected one university each from northern, central, and southern Taiwan using stratified sampling. To generate a sample encompassing a variety of disciplines, this study recruited students enrolled in general education courses as the study participants. A total of 798 physical copies of the questionnaire were distributed, with 758 valid copies eventually returned, yielding a response rate of $95 \%$.

\subsection{Data Analysis}

The study used SPSS 20 for statistical data processing. The reliability test, using Cronbach's alpha measurement, was performed to assess the internal consistency of the formal questionnaire.

For the primary hypothesis (H1), chi-square testing and multinomial logistic regression (MLR) were adopted to examine the relationship between aesthetic experience (IV) and ego identity (DV) subgroups. Based on their average scores in the AES section through the k-means clustering algorithm, respondents were divided into three groups as follows: frequent, moderate, and infrequent. The higher the score, the more elevated the frequency of a participant's aesthetic experience; consequently, a higher tally predicts a more advanced aesthetic sensitivity. In addition, to classify the respondents' ego identity status, this study followed the principles proposed by Balistreri et al. [58], the original developers of EIPQ. Specifically, each respondent received an exploration score and a commitment score. The median mark of the exploration dimension and that of the commitment dimension were used as the dividing numbers that were utilized to differentiate the respondents. Respondents whose totals in each of the two dimensions were above the medians were placed in the subgroup identity achievement. Respondents whose exploration scores were higher than the exploration median, but who achieved lower commitment scores than the commitment median were classified as the moratorium subgroup. Those whose exploration scores were lower than the exploration median, but whose commitment scores were higher than the commitment median were assigned to the foreclosure subgroup. Finally, participants whose scores were both lower than the medium score were positioned in the subgroup named diffusion.

For the secondary hypothesis (H2), this study tested the variance of mean AES scores in relation to the respondents' sociodemographic information comprising sex, religious beliefs, college major, and monthly allowance through the $t$-test and one-way analysis of variance (ANOVA).

\section{Result}

As shown in Table 1, the Cronbach's alpha of the AES section was 0.91, whereas those of the exploration and commitment dimensions in the EIPQ section were 0.75 and 0.76 , respectively. Overall, the questionnaire developed in this study exhibited stability and had excellent internal consistency. 
Table 1. Items for aesthetic experience scale (AES) and ego identity process questionnaire (EIPQ).

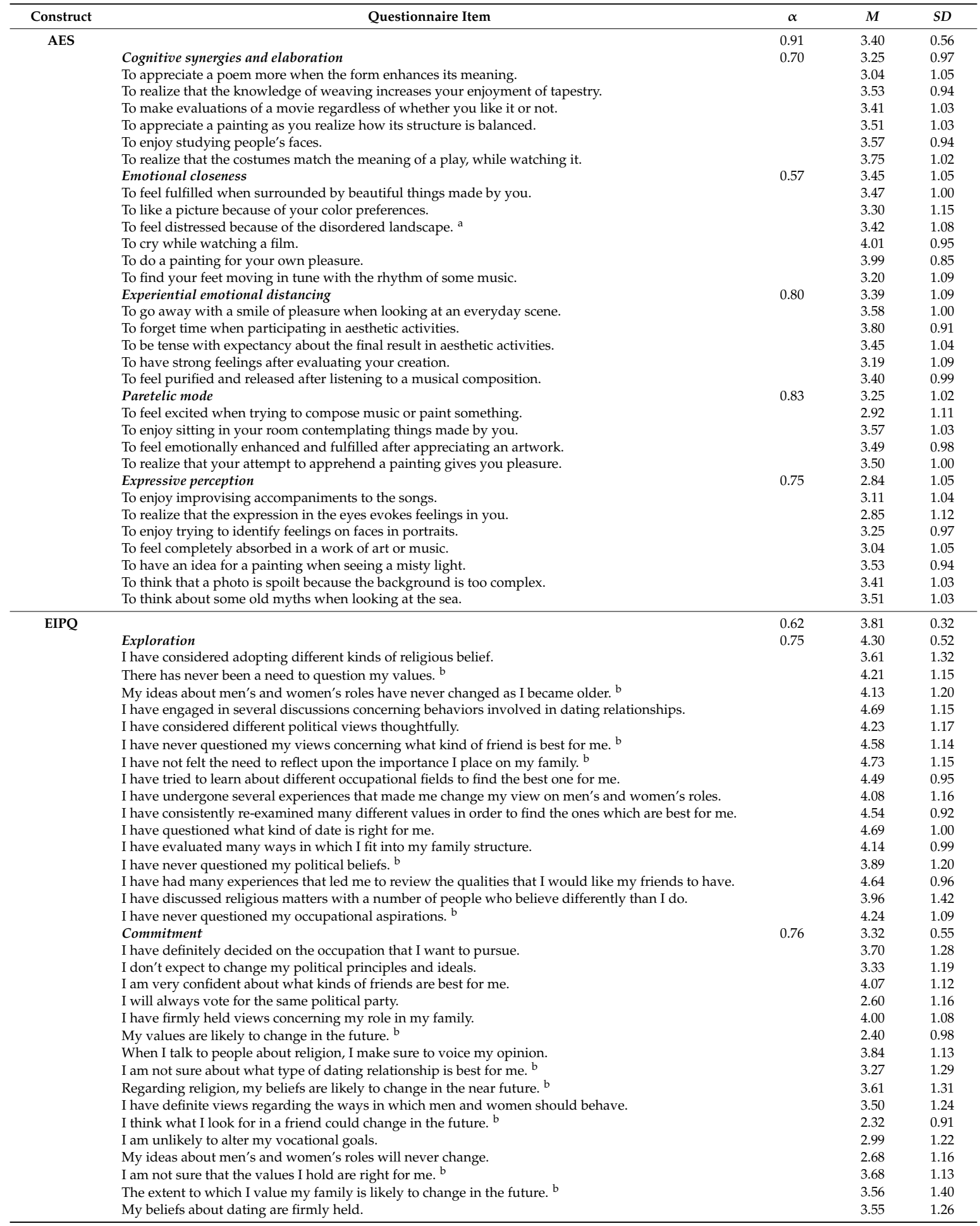

Note: ${ }^{a}$ The content was revised to better fit the city status in Taiwan. ${ }^{b}$ This indicates a negatively-worded item.

\subsection{Profile of Respondents}

Table 2 shows that the male-female ratio of the sample data was approximately $0.8: 1$ (45\% male and 55\% female). Most respondents were aged 19-21 years (90.1\%). Natural science was the most common major among the respondents (41.7\%), followed by social science (30.5\%), human science 
$(15.3 \%)$, and fine arts and design (12.5\%). Most participants had a monthly allowance of US \$100-200 $(30 \%)$, and more than half of the participants had no religious beliefs $(52.8 \%)$.

Table 2. Descriptive statistics for background variables.

\begin{tabular}{|c|c|c|c|c|c|}
\hline Demographic Information & $n$ * & $\%$ & Demographic Information & $n^{*}$ & $\%$ \\
\hline Sex & & & Major & & \\
\hline Male & 337 & 45.0 & Natural science & 303 & 41.7 \\
\hline Female & 412 & 55.0 & Social science & 222 & 30.5 \\
\hline Age (years) & & & Human science & 111 & 15.3 \\
\hline$\geq 27$ & 4 & 0.5 & Fine arts and design & 91 & 12.5 \\
\hline $23-26$ & 69 & 9.3 & Monthly allowance (US\$) ${ }^{1}$ & & \\
\hline $19-22$ & 668 & 90.2 & $<100$ & 78 & 12.9 \\
\hline Year of study & & & $100-200$ & 181 & 30.0 \\
\hline Freshman & 265 & 35.6 & $200-300$ & 155 & 25.7 \\
\hline Sophomore & 175 & 23.4 & $300-400$ & 139 & 23.0 \\
\hline Junior & 209 & 28.0 & $>400$ & 51 & 8.4 \\
\hline Senior & 89 & 11.9 & Religious beliefs & & \\
\hline Other & 9 & 1.1 & No & 384 & 52.8 \\
\hline Citizenship & & & Yes & 343 & 47.2 \\
\hline Taiwanese resident & 709 & 95.5 & & & \\
\hline Overseas Chinese student & 28 & 3.8 & & & \\
\hline International student & 5 & 0.7 & & & \\
\hline
\end{tabular}

\subsection{Classification of Aesthetic Experience Frequency and Ego Identity Status}

As shown in Table 3, through k-means clustering analysis, the top scorers of AES were clustered into the frequent subgroup $(M=4.10, n=207)$; the moderate scorers were delimitated into the moderate subgroup $(M=3.38, n=363)$; and the bottom scorers were designated into the infrequent subgroup $(M=2.63, n=188)$. Furthermore, this study examined the variance of the mean scores among the three subgroups by conducting an ANOVA. The results revealed significant differences among the three subgroups $(F(2754)=1683.97, p<0.001)$. The frequent subgroup had a significantly higher AES score than the moderate and infrequent subgroups, and the moderate subgroup had a significantly higher AES score than the infrequent subgroup. Therefore, the sample clustering approach in this study was reasonable.

Table 3. Classification of aesthetic experience frequency via k-means clustering analysis.

\begin{tabular}{|c|c|c|c|c|c|c|}
\hline Aesthetic Experience Frequency ${ }^{1}$ & $n$ & $\%$ & $M$ & $S D$ & $\operatorname{Max}$ & Min \\
\hline Frequent & 207 & 27.3 & 4.10 & 0.28 & 5.00 & 3.75 \\
\hline Moderate & 363 & 47.9 & 3.38 & 0.20 & 3.71 & 3.04 \\
\hline Infrequent & 188 & 24.8 & 2.69 & 0.28 & 3.00 & 1.57 \\
\hline
\end{tabular}

${ }^{1}$ Based on the results of k-means cluster analysis with the average scores in the aesthetic experience scale (AES) section.

As illustrated in Table 4, in the case of this study, the medians of exploration and commitment were 68 and 53. These two numbers were used to differentiate each respondent's identity status. Following the procedure stated above, this study classified the respondents into four identity positions. The majority of this sample belonged to the moratorium (29.8\%) and foreclosure (27.2\%) categories. A few of the respondents, however, have reached identity achievement $(19.4 \%)$. 
Table 4. Respondent' ego identity process questionnaire (EIPQ) scores and ego identity status.

\begin{tabular}{|c|c|c|c|c|c|c|}
\hline \multirow{2}{*}{ Dimensions of EIPQ ${ }^{1}$} & \multirow{2}{*}{ Total Items } & \multicolumn{5}{|c|}{ Respondent' Scores for Each EIPQ Dimension } \\
\hline & & $\operatorname{Max}$ & Min & $M d n$ & $M$ & $S D$ \\
\hline Exploration & 16 & 96 & 41 & 68 & 68.65 & 8.38 \\
\hline Commitment & 16 & 80 & 23 & 53 & 52.94 & 8.74 \\
\hline Ego identity status ${ }^{2}$ & $n$ & \multicolumn{5}{|c|}{ Percentage (\%) } \\
\hline Achievement & 147 & \multicolumn{5}{|c|}{19.4} \\
\hline Moratorium & 226 & \multicolumn{5}{|c|}{29.8} \\
\hline Foreclosure & 206 & \multicolumn{5}{|c|}{27.2} \\
\hline Diffusion & 179 & \multicolumn{5}{|c|}{23.6} \\
\hline
\end{tabular}

${ }^{1}$ Based on a 6-point Likert-type scale ranging from 1 to 6 for each item, 16 items in total for each dimension.

${ }^{2}$ Based on the classification principle formulated by Balistreri et al. [58], the original developers of EIPQ.

Total sample size $(\mathrm{N})=758$.

\subsection{Hypothesis 1: Individuals Who Have Frequent Aesthetic Experiences Possess a More Mature Ego Identity}

Chi-square testing with a $3 \times 4$ table (Table 5) verified the variations in 4 types of ego identities (DV) based on the frequency of 3 types of aesthetic experiences (IV). The result shows significant differences in ego identity among the frequent, moderate, and infrequent subgroups (chi square $\left[x^{2}\right]$ $=59.028, p<0.001)$. Based on the post-hot testing, in the frequent subgroup, the percentages for achievement $(\operatorname{Adj} R=|4.3|>1.96)$ and moratorium $(\operatorname{Adj} R=|3.6|>1.96)$ were significantly higher than those for foreclosure (Adj $R=|-2.8|>1.96$ ) and diffusion (Adj $R=|-5.0|>1.96$ ). However, no significant difference was found for the moderate subgroup in the four ego identity subgroups. Conversely, the percentages of diffusion (Adj $R=|4.1|>1.96)$ and foreclosure (Adj $R=|1.9|$, closed to 1.96) were partially significantly higher than those of moratorium (Adj $R=|4.3|>1.96$ ) and achievement (Adj $R=|-3.5|>1.96)$ in the infrequent subgroup.

Table 5. Chi-square test of aesthetic experience and ego identity.

\begin{tabular}{|c|c|c|c|c|c|c|}
\hline \multirow{3}{*}{ Ego Identity } & \multicolumn{3}{|c|}{ Aesthetic Experience } & \multirow{3}{*}{ Total $n$} & \multirow{3}{*}{$\chi^{2}(p)$} & \multirow{3}{*}{ Cramer's V $(p)$} \\
\hline & Frequent & Moderate & Infrequent & & & \\
\hline & $n$ & $n$ & $n$ & & & \\
\hline Moratorium & $\begin{array}{c}82 \\
(39.6 \%)^{1}(3.6)^{3}\end{array}$ & $\frac{102}{(28.1 \%)^{1}(-1.0)^{3}}$ & $\frac{42}{(22.3 \%)^{1}(4.3)^{3}}$ & $\begin{array}{c}226 \\
(29.8 \%)\end{array}$ & \multirow{3}{*}{$\begin{array}{c}59.028^{* * *} \\
(<0.001)\end{array}$} & \multirow{3}{*}{$\begin{array}{l}0.197^{* * *} \\
(<0.001)\end{array}$} \\
\hline Diffusion & $\begin{array}{c}23 \\
(11.1 \%)^{2}(-5.0)^{3}\end{array}$ & $\begin{array}{c}91 \\
(25.1 \%)^{1}(0.9)^{3}\end{array}$ & $\begin{array}{c}65 \\
(34.6 \%)^{2}(4.1)^{3}\end{array}$ & $\begin{array}{c}179 \\
(23.6 \%) \\
\end{array}$ & & \\
\hline Total & $\begin{array}{c}207 \\
(100 \%)\end{array}$ & $\begin{array}{c}363 \\
(100 \%)\end{array}$ & $\begin{array}{c}188 \\
(100 \%)\end{array}$ & $\begin{array}{c}758 \\
(100 \%)\end{array}$ & & \\
\hline
\end{tabular}

$N($ Total sample size $)=758 . n=$ observed count. $M=$ mean. ${ }^{* * *} p<0.001 .{ }^{1,2}$ Percentages of errors after Bonferroni correction. ${ }^{3}$ Adjusted residual. Aesthetic experience = Independent variable (IV); Ego identity = Dependent variable (DV).

The results of the MLR (Table 6) were also similar to the findings of the aforementioned chi-square testing. Based on the increased values of odds ratio (OR), people who had more frequent aesthetic experiences tended to be more mature in their ego identity. For instance, in predicting the status of achievement, individuals evaluated as frequent aesthetic experiencers $(\mathrm{OR}=8.620)$ had higher multinomial log-odds than those who were evaluated as moderate $(\mathrm{OR}=2.357)$. More, the log-odds ration values for the frequent status also declined in stages: from the achievement subgroup to the participants positioned in the moratorium subgroup, to those clustered into the foreclosure subgroup $(\mathrm{ORs}=8.620,5.518$, and 1.900, respectively). The diffusion group was treated as a reference group. 
Table 6. Multinomial logistic regression model.

\begin{tabular}{|c|c|c|c|c|c|c|c|c|}
\hline \multirow{2}{*}{ Ego Identity ${ }^{1}$} & \multirow{2}{*}{ Aesthetic Experience } & \multirow{2}{*}{$\beta$} & \multirow{2}{*}{$\begin{array}{l}\text { Std. } \\
\text { err. }\end{array}$} & \multirow{2}{*}{ Wald Chi-Square Test } & \multirow{2}{*}{$p$} & \multirow{2}{*}{$\operatorname{Exp}(\beta) / O R$} & \multicolumn{2}{|c|}{ 95\% Conf. Int. for $\operatorname{Exp}(\beta)$} \\
\hline & & & & & & & Lower Bound & Upper Bound \\
\hline \multirow{3}{*}{ Achievement } & Frequent & 2.154 & 0.354 & $37.043 * * *$ & $<0.001$ & 8.620 & 4.308 & 17.248 \\
\hline & Moderate & 0.857 & 0.303 & $8.033 * *$ & 0.005 & 2.357 & 1.303 & 4.265 \\
\hline & Infrequent & $0^{2}$ & & & & & & \\
\hline \multirow{3}{*}{ Moratorium } & Frequent & 1.708 & 0.308 & $30.749 * * *$ & $<0.001$ & 5.518 & 3.017 & 10.091 \\
\hline & Moderate & 0.551 & 0.245 & $5.058 *$ & 0.025 & 1.735 & 1.073 & 2.804 \\
\hline & Infrequent & $0^{2}$ & & & & & & \\
\hline \multirow{3}{*}{ Foreclosure } & Frequent & 0.642 & 0.316 & $4.131 *$ & 0.042 & 1.900 & 1.023 & 3.526 \\
\hline & Moderate & 0.197 & 0.229 & 0.741 & 0.389 & 1.218 & 0.778 & 1.907 \\
\hline & Infrequent & $0^{2}$ & & & & & & \\
\hline
\end{tabular}

Aesthetic experience $=\mathrm{IV} ;$ Ego identity $=\mathrm{DV}$. OR denotes the odds ratio associated with the effect of a one standard deviation increase in the predictor. ${ }^{* *} p<0.001,{ }^{* *} p<0.01$, and ${ }^{*} p<0.05 .{ }^{1}$ Diffusion was treated as the reference group. ${ }^{2}$ This parameter was set to zero because it is redundant.

In summary, the respondents with high levels of aesthetic experience tended to be clustered into the achievement and moratorium subgroups, whereas those with low levels of aesthetic experience tended to be clustered into the foreclosure and diffusion subgroups. The statistical analysis revealed that aesthetic experience influenced ego identity.

\subsection{Hypothesis 2: Sociodemographic Backgrounds May Influence the Frequency of a Person's Aesthetic Experiences}

Table 7 shows that the mean AES scores of the male and female respondents were 3.29 and 3.50 , respectively. The independent two-sample $t$ test revealed a significant difference between the two mean AES scores under a 95\% confidence interval $(t(749)=-5.364, p<0.001, \mathrm{~d}$ (difference in mean) $=-0.22)$. The female respondents significantly outscored their male counterparts. The mean AES scores of those without and with religious beliefs were 3.36 and 3.45, respectively. The independent $t$ test revealed a significant difference between the two mean AES scores $(t(727)=-2.738, p<0.05, \mathrm{~d}=-0.1)$. The religious respondents outscored their non-religious counterparts.

Table 7. Comparison between sociodemographic information and aesthetic experience frequency via independent $t$ test.

\begin{tabular}{|c|c|c|c|c|c|c|}
\hline Sociodemographic Variable & $n^{\mathrm{a}}$ & $M$ & $S D$ & $t$ & $p$ & $d^{\mathrm{b}}$ \\
\hline Sex & 749 & & & $-5.364^{* * *}$ & 0.000 & -0.22 \\
\hline Male & & 3.29 & 0.56 & & & \\
\hline Female & & 3.50 & 0.54 & & & \\
\hline Religious beliefs & 727 & & & $-2.738 *$ & 0.018 & -0.1 \\
\hline No & & 3.36 & 0.54 & & & \\
\hline Yes & & 3.45 & 0.59 & & & \\
\hline
\end{tabular}

The ANOVA was used to verify the variance in the AES scores according to respondents' college major and monthly allowance. Table 8 shows significant differences among the AES scores for various majors $(F(3723)=23.311, p<0.001)$. Scheffe's post-hoc pairwise comparisons revealed that the mean AES score of fine arts and design students was significantly higher than those of the natural science, social science, and human science students $(p<0.05)$. In addition, the mean AES score of human science students was higher than those of natural science and social science students $(p<0.05)$. However, no significant differences among the mean AES scores were observed between the various brackets of monthly allowance $(F(4599)=0.652, p>0.05)$. 
Table 8. Comparison between sociodemographic information and aesthetic experience frequency via one-way analysis of variance (ANOVA) and post hoc test.

\begin{tabular}{|c|c|c|c|c|c|c|}
\hline Sociodemographic Variable & $n^{\mathrm{a}}$ & $M$ & $S D$ & $F$ & $p$ & Scheffe's Post-Hoc Test \\
\hline Major & 727 & & & $23.311^{* * *}$ & 0.000 & IV > I, II, III \\
\hline Natural science (I) & & 3.28 & 0.57 & & & III > II \\
\hline Social science (II) & & 3.38 & 0.48 & & & \\
\hline Human science (III) & & 3.54 & 0.56 & & & \\
\hline Fine arts and design (IV) & & 3.78 & 0.50 & & & \\
\hline Monthly allowance (US\$) & 604 & & & 0.652 & 0.626 & N/A \\
\hline$<100$ & & 3.35 & 0.59 & & & \\
\hline $100-200$ & & 3.41 & 0.57 & & & \\
\hline $200-300$ & & 3.41 & 0.55 & & & \\
\hline $300-400$ & & 3.43 & 0.59 & & & \\
\hline$>400$ & & 3.52 & 0.6 & & & \\
\hline
\end{tabular}

\section{Discussion}

This study examined the relationship between aesthetic experience and ego identity to verify the common claim in aesthetic theories that aesthetic experience stimulates an individual's ego. A hypothesis of the positive correlation between frequency of aesthetic experiences and ego identity was proposed. The quantitative analysis results confirmed the significantly positive correlation between the frequency of aesthetic experiences and ego identity. Regarding the identity development state, the clustering analysis results revealed that a large proportion of individuals who have frequent aesthetic experiences were at the identity achievement state, whereas only few respondents were at the identity diffusion state. Conversely, a large proportion of individuals with infrequent aesthetic experiences were at identity diffusion; very few respondents were at the identity achievement state. Those with a moderate frequency of aesthetic experiences were distributed among all four types of ego identity without a predominating subgroup. Similarly, the MLR analysis showed that aesthetic experience served as a predictor of one's ego-identity status. Those who were characterized as frequently having aesthetic experiences were more likely to be in identity achievement and quite unlikely to be in diffusion. The hypothesis proposed in this study was supported; aesthetic experiences favor the development of mature ego identity among emerging adults such as college students.

The findings in this study demonstrated the substantial contribution of aesthetic experience to the exploration dimension of ego identity. Theoretically, ego identity can be divided into four quadrants based on two constructs: exploration and commitment $[5,9]$. In this study, the ego identities of the frequent aesthetic experiencer subgroup were mostly classified in the moratorium and achievement subgroups. The common characteristic shared by these two subgroups was their high attribution to exploration. For example, individuals whose ego identity is classified as moratorium actively consider various social values and career options without committing to any one stance. Individuals at the moratorium stage are not only more prone to identity crisis than individuals in the other quadrants are, but they are also more open to investigating life choices [5]. They are experientially-oriented and inclined to dialectic thinking [61]. These characteristics are likely to be stimulated by aesthetic experiences. As reviewed earlier, the art-making process easily arouses self-dialectic thinking [39]. It is also important to note that achievement and moratorium are two statuses most correlated to high psychological well-being in certain ethnic groups [12]. Therefore, a sustainable state of positive living can be expected [1]. Additionally, the respondents who rarely had aesthetic experiences were mostly classified in the diffusion and foreclosure subgroups. The common characteristic shared by these two subgroups was their low attribution to exploration. Therefore, the respondents in these two subgroups were either insensitive to their identity crises or in a false state of enduring their identity crises [5].

In summary, aesthetic experience facilitates the exploration of various topics related to ego identity. Individuals lacking aesthetic experience are likely to commit to a range of social identities without 
comprehensively exploring them. This idea echoes the point made by Smolewska et al. [51] that a person who is responsive to aesthetic encounters is often more open to experience. An enhanced awareness of artistry seems to expand an individual's opportunities of exploring new ideas, inventions, and adventures, and vice versa. Multifaceted aesthetic experiences may provide people with prospects of discovering their identities with respects to aspects such as spirituality, politics, family, friendships, sexual roles, etc. Identity formation is stimulated when one is creating art or even when a person is merely absorbed in the beauty of the natural environment.

As the first hypothesis of the study was confirmed, this study attempted to identify what type of person is more likely to experience the aesthetic. Sociodemographically, the findings of this study revealed that women, fine arts and design majors, and religious individuals are more likely to have frequent aesthetic experiences. However, this study found that economic status was not an influential factor for frequency of aesthetic experience, thereby confirming that economic capital and cultural capital are not always equal [68]; money cannot or may not have been invested in amassing aesthetic experience.

The argument of biological determinism should be avoided in discussions about why women have a higher frequency of aesthetic experiences than men. The research conducted by Aron and Aron [52] elucidated that a higher percentage of women than men were found to be highly sensitive. However, no previous studies on infants have demonstrated such a difference because of gender. Therefore, this tendency might develop through socialization. Aron and Aron [52] surmised that in traditional patriarchal societies, women were generally more encouraged to express their feelings than men. Since aesthetic sensitivity is found to be one of the components of sensory-processing sensitivity [51], the social attitude toward a young person's aesthetic sensitivity may also be different based on gender. As a result, women are more aesthetically sensitive than men. Additionally, the phenomenon that females are generally more developed than males in ego-identity status [14] may be the consequence of more frequent aesthetic experiences that female students possess.

Also from a social perspective, fine arts and design students have more exposure to art appreciation than other college majors and are regarded as a group with rich cultural capital [68]. These students are supposedly familiar with the knowledge system of art and have received a certain degree of training in artistic expression. In contrast to other college majors, fine arts and design students theoretically have a higher level of art competence. The findings of this study suggest that art education not only cultivates artistic talent and taste but also develops individuals with strong aesthetic sensitivity. Stamatopoulou [64] also reported that aesthetic experience is strongly correlated with art familiarity (Pearson's $r=0.38, p<0.001$ ) and perceived art competence (Pearson's $r=0.50, p<0.001$ ). However, this study found that human science students are more likely to experience aesthetics than are social science students, and social science students are more likely to experience aesthetics than are natural science students. This finding may reflect not only the contrasting closeness of various disciplines to aesthetic experience but also the contrasting efforts of each discipline to develop aesthetic sensitivity. Natural phenomena contain a wealth of aesthetic possibilities, as evidenced by academic works on environmental aesthetics [49,69-71]. Whether natural science students' lack of aesthetic experiences can be attributed to the teaching philosophies and methods of natural science disciplines requires further clarification.

The phenomenon of religious individuals having aesthetic experiences more frequently than non-religious individuals may reflect the similarity between religious experience and aesthetic experience. Related discourses in philosophical and psychological theories that define and describe aesthetic experience can be found. For example, Deweyan's philosophy asserts that aesthetic experience often exhibits religious characteristics, and vice versa [22,72]. The concept of peak experience proposed by Maslow [24] encompasses aesthetic experience, creative experience, and religious experience. Similarly, flow experience is a spiritual state commonly mentioned in relation to creative and religious activities $[56,57,73]$. Therefore, aesthetic experience and religious experience must have some degree of similarity because both are optimal catalysts for individuals to reach their optimal spiritual 
pathway. Even though excessively institutionalized religious belief may limit the sensual aspect of a religion [22,24], affiliating to a certain religion may still provide a better chance for an individual to access mystic and spiritual experiences.

\section{Conclusions}

This study confirmed that aesthetic experience facilitates an individual's maturation of ego identity. The frequency of aesthetic experiences is almost proportional to the developmental status of ego identity. In particular, aesthetic experience significantly contributes to the exploration dimension of ego identity. Aesthetic experience seems to provide a special opportunity to discover an individual's identity. Conversely, individuals lacking aesthetic experience are prone to trust authority and make commitments without exploring other values and are far from acknowledging and overcoming identity crises. The findings of this study revealed that aesthetic experience is a catalyst for self-exploration, self-making, and self-development of an identity.

An identity achiever is one who has an integral and static point of view of who he/she is, where he/she is from, and what the future holds for him/her. The self-centered vertical axis of psychologically sustainable development is fulfilled through such accomplishments [1]. This study demonstrates that aesthetic experiences are valuable for strengthening this process. With an updated view of sustainability, which focuses more on promotion than prevention [1], the richness inherent in aesthetic experiences promises individuals an infinite source of sustainable development.

In addition, this study identified that women, fine arts and design majors, and religious individuals are more likely to experience aesthetics. Although this paper initially claims that artistic experience is only one type of aesthetic experience, professional art training evidently cultivates the ability to sense aesthetic experience comprehensively. Also, the findings of this study revealed that religious experience and aesthetic experience share a common psychological or spiritual cognitive pathway.

The findings mentioned above show some educational implications. Aesthetic experiences are a critical stimulus to ego identity development and should not only be the privilege of those who major in art and design. Since aesthetic experiences occur in diverse circumstances, social science and natural science disciplines should offer an equal potential to access the aesthetic. Therefore, instructors' approaches to pedagogy are crucial. In addition, both formal and informal education should encourage males to embrace their aesthetic interests and sensitivity, which may contribute to a developmental pace equal to that of females.

Findings of this research are based on responses from Taiwanese college students. This sample may not be able to describe individuals from other cultural backgrounds. Therefore, a cross-cultural comparative study may be conducted in the future to examine the correlations between aesthetic experiences and the development of ego identity. Similarly, those who reported being affiliated to certain religious groups may very likely be Buddhists, Taoists, or other followers of local religions. Since different religions present different spiritual experiences, the resonance between divine experiences and aesthetic experiences should vary by religion. To investigate the psychological similarities between religious experiences and aesthetic experiences, future studies may take different religions into consideration. Additionally, to understand how certain sociodemographic attributions affect one's frequency of having an aesthetic experience, the phenomenon needs to be approached from multiple perspectives. Thus, the effect of gender on aesthetic sensitivity may be examined through biological, evolutionary, psychological, and social approaches. Likewise, natural science students' lack of aesthetic experiences may require a thorough investigation on the nature of the discipline and how it is conveyed through teaching methods.

Author Contributions: C.-Y.Y. conceived the study and developed the theoretical framework. C.-Y.Y. and P.-C.W. designed the research method. C.-Y.Y. coordinated the data collection and data processing procedure. C.-Y.Y. and P.-C.W. interpreted the results and contributed to the final manuscript. 
Funding: The research project reported in this paper was funded partially by the Ministry of Science and Technology of Taiwan (MOST 104-2410-H-007-085) and partially by Nanhua University (Y103001071).

Acknowledgments: We are grateful to the students of the National Tsing Hua University, National Chung Hsing University, and National Chiayi University who participated in this study. We also appreciate faculty members in these universities who helped to distribute the questionnaires in their general education courses. We are thankful to the research assistants Yi-Ting Tsai and Yuan-Tai Chen for their thoughtful help. Last but not the least, we would like to thank the anonymous reviewers for their insightful comments to improve the quality of the paper.

Conflicts of Interest: The authors declare no conflict of interest.

\section{References}

1. Di Fabio, A. The psychology of sustainability and sustainable development for well-being in organizations. Front. Psychol. 2017, 8, 1534. [CrossRef] [PubMed]

2. Di Fabio, A. Positive healthy organizations: Promoting well-being, meaningfulness, and sustainability in organizations. Front. Psychol. 2017, 8, 1938. [CrossRef] [PubMed]

3. Erikson, E.H. Identity and the Life Cycle; W.W. Norton Company: New York, NY, USA, 1959.

4. Erikson, E.H. Identity: Youth and Crisis; W.W. Norton Company: New York, NY, USA, 1968.

5. Marcia, J.E. Development and validation of ego-identity status. J. Personal. Soc. Psychol. 1966, 3, 551-558. [CrossRef]

6. Grotevant, H.D.; Cooper, C.R. Assessing adolescent identity in the areas of occupation, religion, politics, friendships, dating, and sex roles: Manual for administration and coding of the interview. JSAS Cat. Sel. Doc. Psychol. 1981, 11, 52-53.

7. Grotevant, H.D.; Thorbecke, W.; Meyer, M.L. An extension of Marcia's identity status interview into the interpersonal domain. J. Youth Adolesc. 1982, 11, 33-47. [CrossRef] [PubMed]

8. Marcia, J.E.; Friedman, M.L. Ego identity status in college women. J. Personal. 1970, 38, 249-263. [CrossRef]

9. Bilsker, D.; Schiedel, D.; Marcia, J.E. Sex differences in identity status. Sex Roles 1988, 18, 231-236. [CrossRef]

10. Luyckx, K.; Schwartz, S.J.; Rassart, J.; Klimstra, T.A. Intergenerational associations linking identity styles and processes in adolescents and their parents. Eur. J. Dev. Psychol. 2015, 13, 67-83. [CrossRef]

11. Co^te', J.E.; Bynner, J.M. Changes in the transition to adulthood in the UK and Canada: The role of structure and agency in emerging adulthood. J. Youth Stud. 2008, 11, 251-268. [CrossRef]

12. Co^te', J.E.; Levine, C.G. Identity Formation, Agency, and Culture: A Social Psychological Synthesis; Lawrence Erlbaum Associates: Mahwah, NJ, USA, 2002.

13. Abu-Rayya, H.M. Ethnic identity, ego identity, and psychological well-being among mixed-ethnic Arab-European adolescents in Israel. Brit. J. Dev. Psychol. 2006, 24, 669-679. [CrossRef]

14. Schwartz, S.J.; Beyers, W.; Luyckx, K.; Soenens, B.; Zamboanga, B.L.; Forthun, L.F.; Hardy, S.A.; Vazsonyi, A.T.; Ham, L.S.; Kim, S.Y.; et al. Examining the light and dark sides of emerging adults' identity: A study of identity status differences in positive and negative psychosocial functioning. J. Youth Stud. 2011, 40, 839-859. [CrossRef] [PubMed]

15. Janarthanam, D.; Gnanadevan, R. Gender Differences in Ego-Identity Status of Higher Secondary Students. IJTER 2014, 3, 14-18.

16. Cakir, S.G.; Aydin, G. Parental attitudes and ego identity status of Turkish adolescents. Adolescence 2005, 40, 847-859. [PubMed]

17. Klaczynski, P.A.; Fauth, J.M.; Swanger, A. Adolescent identity: Rational vs. experiential processing, formal operations, and critical thinking beliefs. J. Youth Adolesc. 1998, 27, 185-207. [CrossRef]

18. Krettenauer, T. The role of epistemic cognition in adolescent identity formation: Further evidence. J. Youth Adolesc. 2005, 34, 185-198. [CrossRef]

19. Hammermeister, K. The German Aesthetic Tradition; Cambridge University Press: Cambridge, UK, 2002.

20. Leder, H.; Belke, B.; Oeberst, A.; Augustin, D. A model of aesthetic appreciation and aesthetic judgments. Br. J. Psychol. 2004, 95, 489-508. [CrossRef] [PubMed]

21. Yu, C.-Y. Aesthetic experience and its profound interaction with the self/ego. Res. Arts Educ. 2016, 32, 103-132.

22. Dewey, J. Art as Experience; The Berkley Publishing Group: New York, NY, USA, 1934.

23. Koltko-Rivera, M.E. Rediscovering the later version of Maslow's hierarchy of needs: Self-transcendence and opportunities for theory, research, and unification. Rev. Gen. Psychol. 2006, 10, 302-317. [CrossRef] 
24. Maslow, A.H. Religions, Values, and Peak-Experiences; Ohio State University Press: Columbus, OH, USA, 1964.

25. Maslow, A.H. Motivation and Personality; Harper \& Row: New York, NY, USA, 1954.

26. Maslow, A.H. The Farther Reaches of Human Nature; Arkana: New York, NY, USA, 1993.

27. Ward, D.; Lasen, M. An overview of needs theories behind Consumerism. J. Appl. Econ. Sci. 2009, 4, 137-155.

28. Garrels, G. Drawing from the Modern: 1945-1975; Museum of Modern Art: New York, NY, USA, 2005.

29. Elkins, J. Pictures E Tears: A History of People Who Have Cried in Front of Paintings; Routledge: New York, NY, USA, 2001.

30. Ferrucci, P. Beauty and the Soul: The Extraordinary Power of Everyday Beauty to Heal Your Life; Jeremy P. Tarcher: New York, NY, USA, 2010.

31. Pépin, C. Quand la Beauté Nous Sauve; Marabout: Paris, France, 2014.

32. Benson, C. The Absorbed Self-Pragmatism, Psychology and the Aesthetic Experience; Harvester Wheatsheaf: New York, NY, USA, 1993.

33. Maquet, J. The Aesthetic Experience; Yale University Press: New Haven, CT, USA, 1988.

34. Child, I.L. Personality correlates of esthetic judgment in college students. J. Personal. 1965, 33, 476-511. [CrossRef]

35. Waterman, A.S.; Goldman, J.A. A longitudinal study of ego identity development at a liberal arts college. J. Youth Adolesc. 1976, 5, 361-369. [CrossRef] [PubMed]

36. Sirois, F.O.J. Aesthetic experience. Int. J. Psychoanal. 2008, 89, 127-142. [CrossRef] [PubMed]

37. Winnicott, D.W. Psychoses and child care. Br. J. Med. Psychol. 1953, 26, 68-74. [CrossRef] [PubMed]

38. Winnicott, D.W. Playing and Reality; Tavistock Publications: London, UK, 1971.

39. Hagman, G. Aesthetic Experience: Beauty, Creativity, and the Search for the Ideal; Rodopi: Leiden, The Netherlands, 2005; Volume 5.

40. Vessel, E.A.; Starr, G.G.; Rubin, N. Art reaches within: Aesthetic experience, the self and the default mode network. Front. Neurosci. 2013, 7, 1-9. [CrossRef] [PubMed]

41. Kupfer, J. Experience as Art: Aesthetics in Everyday Life; SUNY Press: New York, NY, USA, 1983.

42. Leddy, T. Everyday surface aesthetic qualities: "Neat," "messy," "clean," "dirty". J. Aesthet. Art Crit. 1995, 53, 259-268. [CrossRef]

43. Novitz, D. The Boundaries of Art: A Philosophical Inquiry into the Place of Art in Everyday Life; Temple University Press: Philadelphia, PA, USA, 1992.

44. Sartwell, C. The Art of Living: Aesthetics of the Ordinary in World Spiritual Traditions; SUNY Press: New York, NY, USA, 1995.

45. Consoli, G. The emergence of the modern mind: An evolutionary perspective on aesthetic experience. J. Aesthet. Art Crit. 2014, 72, 37-55. [CrossRef]

46. Kant, I. Critique of Judgment; Pluhar, W.S., Translator; Hackett Publishing: Indianapolis, IN, USA, 1987.

47. Hepburn, R. 'Being' as a concept of aesthetics. Br. J. Aesthet. 1968, 8, 138-146. [CrossRef]

48. Hepburn, R. Contemporary aesthetics and the neglect of natural beauty. In The Aesthetics of Natural Environments; Carlson, A., Berleant, A., Eds.; Broadview Press: Peterborough, ON, Canada, 2004; pp. 44-62.

49. Hepburn, R. Landscape and the metaphysical imagination. In The Aesthetics of Natural Environments; Carlson, A., Berleant, A., Eds.; Broadview Press: Peterborough, ON, Canada, 2004; pp. 127-140.

50. Cheng, C.Y. The yi-jing and yin-yang way of thinking. In The Routledge History of Chinese Philosophy; Mou, B., Ed.; Routledge: London, UK, 2008; pp. 71-106.

51. Smolewska, K.A.; McCabe, S.B.; Woody, E.Z. A psychometric evaluation of the highly sensitive person scale: The components of sensory-processing sensitivity and their relation to the BIS/BAS and "Big Five". Personal. Individ. Differ. 2006, 40, 1269-1279. [CrossRef]

52. Aron, E.N.; Aron, A. Sensory-processing sensitivity and its relation to introversion and emotionality. J. Personal. Soc. Psychol. 1997, 73, 345-368. [CrossRef]

53. Costa, P.T.; McCrae, R.R. Revised NEO Personality Inventory (NEO PI-R) and NEO Five-Factor Inventory (NEO-FFI); Psychological Assessment Resources: Odessa, FL, USA, 1992.

54. Bourdieu, P. Artistic taste and cultural capital. In Culture and Society: Contemporary Debates; Alexander, J., Seidman, S., Eds.; Cambridge University Press: New York, NY, USA, 1990; pp. 205-215.

55. Duffy, R.A. An analysis of aesthetic sensitivity and creativity with other variables in grades four, six, eight, and ten. J. Educ. Res. 1979, 73, 26-30. [CrossRef]

56. Csikszentmihalyi, M. Flow: The Psychology of Optimal Experience; Harper \& Row: New York, NY, USA, 1990. 
57. Csikszentmihalyi, M. Creativity: Flow and the Psychology of Discovery and Invention; Harper Perennial: New York, NY, USA, 1996.

58. Balistreri, E.; Busch-Rossnagel, N.A.; Geisinger, K.F. Development and preliminary validation of the Ego Identity Process Questionnaire. J. Adolesc. 1995, 18, 179-190. [CrossRef]

59. Bourne, E. The state of research on ego identity: A review and appraisal. Part I. J. Youth Adolesc. 1978, 7, 223-251. [CrossRef] [PubMed]

60. Bourne, E. The state of research on ego identity: A review and appraisal. Part II. J. Youth Adolesc. 1978, 7, 371-392. [CrossRef] [PubMed]

61. Stephen, J.; Fraser, E.; Marcia, J.E. Moratorium-achievement (Mama) cycles in lifespan identity development: Value orientations and reasoning system correlates. J. Adolesc. 1992, 15, 283-300. [CrossRef]

62. Streitmatter, J. Gender differences in identity development: An examination of longitudinal data. Adolescence 1993, 28, 55-66. [PubMed]

63. Chang, C.H. Ego identity status in Chinese university students: A test of the validity of Marcia's categorization for ego identity. Bull. Educ. Psychol. 1982, 15, 31-46.

64. Stamatopoulou, D. Integrating the philosophy and psychology of aesthetic experience: Development of the aesthetic experience scale. Psychol. Rep. 2004, 95, 673-695. [CrossRef] [PubMed]

65. Crocetti, E.; Fermani, A.; Pojaghi, B.; Meeus, W. Identity formation in adolescents from Italian, mixed, and migrant families. Child Youth Care Forum 2011, 40, 7-23. [CrossRef]

66. Dunkel, C.S.; Papini, D.R. The role of ego-identity status in mating preferences. Adolescence 2005, 40, 489-501. [PubMed]

67. Goldstein, S.N. The exploration of spirituality and identity status in adolescence. New Scholarsh. Hum. Serv. 2010, 9, 1-22.

68. Bourdieu, P. The forms of capital. In Handbook of Theory and Research for the Sociology of Education; Richardson, L.C., Ed.; Nice, R., Translator; Greenwood Press: New York, NY, USA, 1986; pp. 241-258.

69. Burke, E. A Philosophical Enquiry into the Origin of Our Ideas of the Sublime and Beautiful; Oxford University Press: Oxford, UK, 1757.

70. Berleant, A. Living in the Landscape: Toward an Aesthetics of Environment; University Press of Kansas: Lawrence, KS, USA, 1997.

71. Leopold, A. A Sand County Almanac and Sketches Here and There; Oxford University Press: New York, NY, USA, 1989.

72. Alexander, T.M. John Dewey's Theory of Art, Experience, and Nature: The Horizons of Feeling; SUNY Press: New York, NY, USA, 1987.

73. Neitz, M.J.; Spickard, J.V. Steps toward a sociology of religious experience: The theories of Mihaly Csikszentmihalyi and Alfred Schutz. Sociol. Anal. 1990, 51, 15-33. [CrossRef] 